\title{
O papel da logística na exportação brasileira de flores de corte ${ }^{1}$
}

\author{
LILIAN CRISTINA ANEFALOS ${ }^{2}$ e JOSÉ VICENTE CAIXETA FILHO ${ }^{3}$
}

\begin{abstract}
RESUMO
O objetivo deste trabalho é compreender o papel dos integrantes da cadeia de exportação de flores de corte e dos principais processos logísticos que a compõem. Constatou-se que o setor de flores necessita de grande interação entre os agentes, viabilizando-se as exportações brasileiras a longo prazo. Para que ocorra o aprimoramento de cada uma das etapas da exportação, há necessidade de monitoramento contínuo do produto perecível, por meio da otimização do processo logístico ao longo de toda a cadeia. Por outro lado, verificou-se que essas alterações constituem-se num processo árduo, para que os padrões internacionais de qualidade e cuidados pós-colheita sejam seguidos, obtendo-se preços mais competitivos no mercado externo. Há a necessidade, portanto, de mudanças culturais e tecnológicas garantindo-se a aceitabilidade do produto brasileiro no exterior e, conseqüentemente, sua valorização no mercado doméstico.
\end{abstract}

Palavras-chave: flor de corte, logística, exportação.

\section{ABSTRACT \\ The logistics role for Brazilian exportation of cut flower}

The objective of this paper is to understand the role of the components of cut-flower exportation chain and the main logistical processes involved. It was verified that a high integration among agents is required in the flower sector so that Brazilian exportations become feasible in the long run. The improvement of each phase of the exportation requires a continuous inspection of perishable product by means of the logistic process optimization throughout the chain. However, in order to make these products more competitive in the external market, the necessary alterations leading to the compliance with international quality standards and post-harvest cares depend on a hard process. Thus, cultural and technological changes are called for to guarantee the acceptance of the Brazilian product in foreign countries and, consequently, its valorization in the domestic market.

Key-words: cut flower, logistics, exportation.

\section{INTRODUÇÃO}

A produção mundial de flores está se disseminando para regiões não consideradas tradicionais no seu cultivo, revelando-as como grandes exportadoras. De acordo com MOTOS (2000b), além de Holanda, Itália, Dinamarca, Japão, destacam-se, atualmente, países como Colômbia, Itália, Israel, Bélgica, Costa Rica, Canadá, EUA, Quênia e Alemanha.

O grande diferencial da Holanda, segundo GÓES (1997), deve-se, principalmente, ao sofisticado e eficiente sistema logístico de distribuição e comercialização, que tem viabilizado o envio de pedidos dos seus clientes na Europa e nos outros continentes em tempo hábil.

Os principais países exportadores da América Latina (Colômbia, Costa Rica e Equador) buscam consolidar seus produtos, principalmente nos mercados europeu e norte-americano. De acordo com dados de 1997 a 2000, publicados por PATHFAST (2001) e reproduzidos na Figura 1, observa-se que, com relação aos bulbos, a Costa Rica concentra a maioria das exportações com destino ao mercado europeu. Em 2000, seu valor comercializado para a Europa foi da ordem de 25 milhões de dólares, contra 142 mil dólares e 24 mil dólares das exportações da Colômbia e do Equador, respectivamente. O valor

\footnotetext{
${ }^{1}$ Artigo baseado na tese de doutorado da primeira autora sob orientação do segundo autor.

${ }^{2}$ Pesquisadora Científica do Instituto de Economia Agrícola. Doutora. Av. Miguel Stéfano, 3900, Água Funda, 04301-903 São Paulo (SP). E-mail: 1canefal@iea.sp.gov.br

${ }^{3}$ Professor Titular do Departamento de Economia, Administração e Sociologia da ESALQ/USP. Av. Pádua Dias, 11. C.P. 9, 13418-900 Piracicaba - (SP). E-mail: jvcaixet@esalq.usp.br.
} 


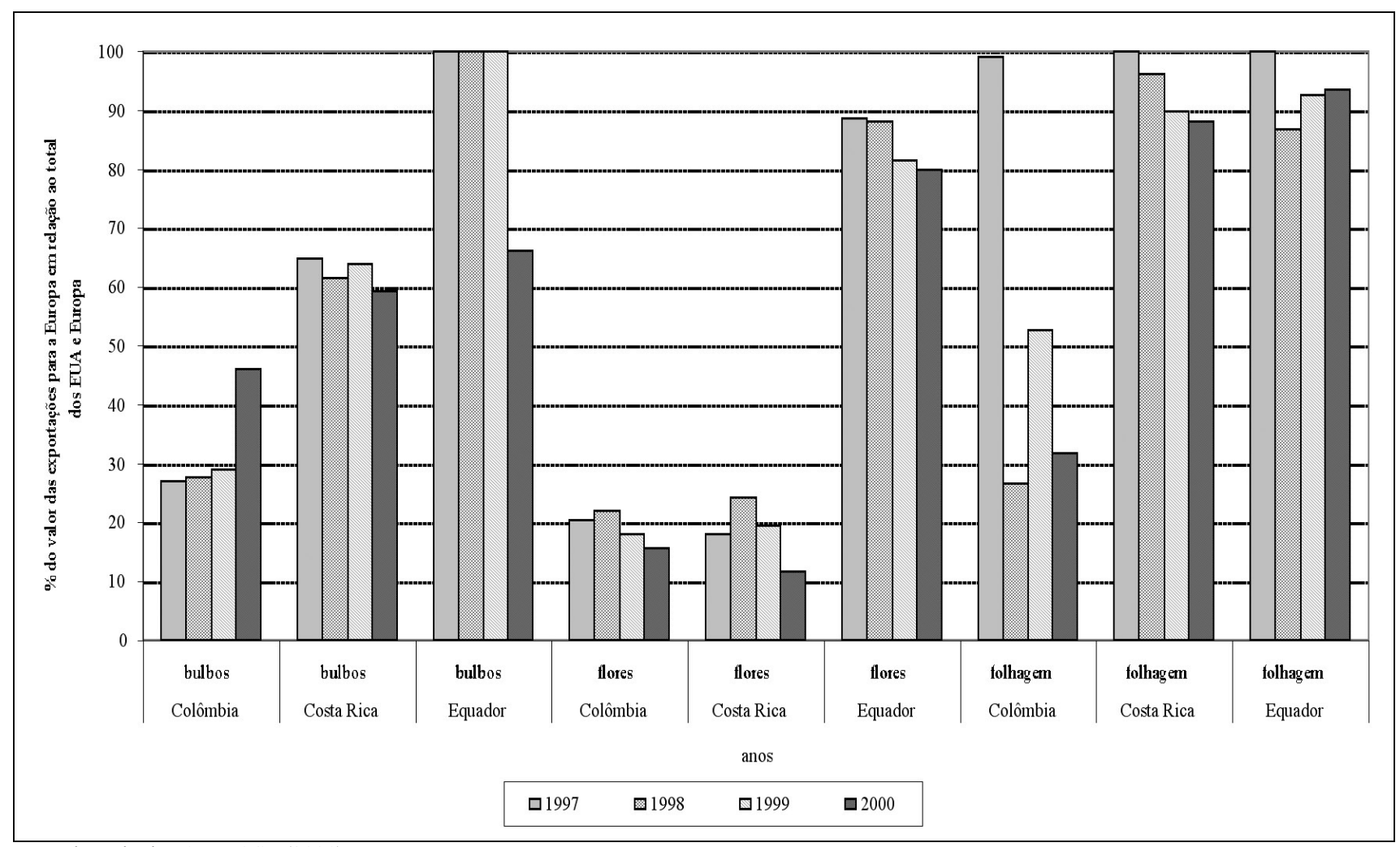

Fonte: adaptado de PATHFAST (2001)

${ }^{1}$ Para os anos de 1999 e 2000 foram considerados os seguintes países para compor o mercado europeu: Alemanha, Áustria, Bélgica, Dinamarca, Espanha, Finlândia, França, Grécia, Holanda, Irlanda, Itália, Portugal, Reino Unido, Suiça, Suécia. Em 1998, não foi incluída a Irlanda e em 1997 foram excluídas a Grécia, Finlândia, Irlanda, Portugal e Suíça, por não haver informações sobre esses países na referida base de dados.

Figura 1. Porcentagem do valor obtido das exportações de bulbos, flores e folhagens para a Europa em relação ao seu total exportado para os mercados norte-americano e europeu.

exportado de flores de corte colombianas, para os EUA, cresceu 13\% em 2000 com relação a 1997, representando $84 \%$ do seu valor total exportado nesse ano (por volta de 431 milhões de dólares), com relação ao total comercializado nos mercados americano e europeu.

Apesar de o Equador ter redirecionado uma pequena parcela de suas exportações para os EUA, em 2000 ainda $80 \%$ do valor total de flores de corte eram exportados para a Europa, totalizando 483 milhões de dólares. A Costa Rica destaca-se, também, pelas suas exportações de folhagens de corte para a Europa, quase duas vezes superior ao valor atingido com a venda de bulbos. Em relação aos outros dois países, Colômbia e Equador, esse produto também é muito pouco representativo ao compará-lo com o valor obtido com a comercialização de flores de corte para a Europa. De 1997 a 2000 esses países tiveram tendência de queda nas exportações de bulbos, cujos valores já eram pouco significativos no início do período em relação aos demais produtos destinados ao mercado europeu.
Como os consumidores europeus são exigentes quanto à origem e qualidade do produto que adquirem no mercado, países da América Latina, tais como Colômbia, Costa Rica e Equador, têm se preocupado em obter o certificado ambiental - selo verde - relacionado ao correto manejo ambiental e trabalhista do setor de flores. No entanto, de acordo com LUCAS (2001), tais iniciativas são ainda incipientes e não envolvem uma parte significativa dos produtores. No Brasil, em contraposição a essas medidas, o uso intensivo de defensivos químicos dificulta a obtenção do selo ambiental, uma vez que a sua utilização indiscriminada pode gerar problemas de saúde em funcionários das empresas, conforme relatado por WALT (2001).

De acordo com DEMARCHI (2001), o bom desempenho dos países andinos deve-se ao fato de usufruírem vantagens comerciais oferecidas pelos países europeus, principalmente em relação às tarifas de importação (praticamente nulas). Entre a Colômbia e os Estados Unidos há uma política similar, cujo objetivo central é combater 
a disseminação do plantio de coca através da diversificação das culturas. Conforme FLORICULTURE AND NURSERY CROPS SITUATION AND OUTLOOK YEARBOOK (2002), os Estados Unidos têm importado aproximadamente $60 \%$ das flores cortadas, a partir de 2000. Do total importado de rosas pelos Estados Unidos nesse ano, $61 \%$ originaram-se da Colômbia, de acordo com PATHFAST (2001).

Esse tratamento preferencial, conforme WALT (2001), não ocorre com o Brasil, que sofre sobretaxas que oscilam entre 1,60 e 11,20\%, em função do nível de abastecimento, para colocar seus produtos na Europa. Dessa forma, para que o Brasil se torne mais competitivo no exterior, deve haver redução de custos, com investimentos crescentes em tecnologia e em diferenciação de produtos.

Conforme WALT (2001), a concorrência internacional está se acirrando, pois as empresas holandesas estão buscando melhorar a sua produtividade com o uso de tecnologias mais avançadas e a instalação de plantações em regiões mais propícias ao cultivo de flores, como é o caso do continente africano (Zimbábue e Quênia) e de Israel. De acordo com BRITISH COLUMBIA(2003), alguns países da América Central e do Sul tiveram elevação de sua produção de flores em função de seus custos de produção menores, relacionados às condições climáticas favoráveis e baixos salários, e também aos custos de transporte, como é o caso da Colômbia, que é o segundo maior exportador de flores de corte depois da Holanda.

O bouquet é outro produto que está sendo valorizado nos Estados Unidos; o valor agregado, em geral, é maior que o das flores de corte sem esse arranjo, e está sendo oferecido também no varejo, de acordo com MILLER (2003).

Por um lado, há alternativas para incremento do produto final, e, por outro, há a necessidade de investimento por parte dos integrantes da cadeia para a produção e distribuição adequadas das flores. Em estudos conduzidos no Quênia, conforme HUGHES (2000), observou-se que os grandes produtores exportavam diretamente para Alemanha, Reino Unido e Holanda, por meio de canais de fornecimento totalmente integrados que garantiam rastreabilidade, controle de qualidade, espaço de cargas nos vôos e redução nos custos, devido ao envolvimento de um menor número de players na distribuição. Em contraposição, os pequenos produtores seriam intermediados por agentes, com meios de propaganda menos eficientes e com riscos mais elevados para o embarque de suas mercadorias nos vôos desejados. De acordo com
MACHADO (2000) a rastreabilidade está "relacionada à capacidade de se identificar o produto, em termos locacionais, de seus atributos, por meio de um sistema de codificação impresso no mesmo".

Há diversos riscos envolvidos na comercialização de flores para outros países. Por se tratar de um produto perecível, o tipo de transporte mais eficiente depende da rota e do destino das flores, predominando aviões e caminhões. As falhas ocorridas durante o trajeto até atingir o consumidor final, poderão refletir em perdas para cada um dos agentes dessa cadeia, dificultando a entrada do produto em países estrangeiros. Essas falhas podem ser ocasionadas por atraso no transporte, como, por exemplo, por engarrafamento no trânsito, superlotação ou recusa em embarcar flores em embalagens não adequadas (sem pallets), ou mesmo pela escolha de operadores não especializados.

No âmbito internacional, a inserção de empresas especializadas no transporte de flores, tais como Fedex e United Parcel Service, e de empresas importadoras de flores da América do Sul, nos últimos anos, têm contribuído para reduzir problemas com transporte aéreo. No Brasil a inconstância nos embarques de flores constituise um fator limitante para a exportação brasileira. Como as flores possuem menor valor agregado em relação a produtos industrializados, tais como os eletrônicos e componentes de máquinas, conforme BARLETTA (1995), no Brasil a sua distribuição aérea não é priorizada, apesar de ser produto perecível.

Para que as flores brasileiras elevem sua participação no mercado internacional, o setor terá que enfrentar restrições, dentre as quais se destaca a adequação a padrões de qualidade e fitossanitários. Em relação ao mercado externo, CLARO (1998) destaca que há espécies, tais como orquídeas, bromélias e flores de cerrado, que têm potencial para exportação, apesar de serem ainda pouco exploradas no Brasil. Conforme BRASIL (2004), a exportação de flores e plantas foi de 13 milhões de dólares em 1999, 11,9 milhões de dólares em 2000 e 19,4 milhões de dólares em 2003. Dentre os produtos básicos exportados e países destino, de acordo com MOTOS (2000a), pode-se relacionar:

a) mudas de crisântemos (Holanda, Itália, Inglaterra, Japão, Dinamarca, Noruega, Argentina, Paraguai e Uruguai);

b) bulbos de gladíolos (Holanda, México, Chile e Uruguai);

c) bulbos de Amaryllis (Holanda, Estados Unidos, Argentina e México); 
(Holanda);

d) mudas de begônias (Holanda); bulbos de lírios

e) mudas de violetas (Holanda);

f) bulbos diversos (Holanda);

g) mudas de Calathea (Holanda);

h) mudas de forrações diversas (diversos países da Europa).

Nos últimos anos tem havido busca por ampliação na inserção das flores de corte em vários países e por consolidação em mercados consumidores, como é o caso da Holanda e dos EUA. Há metas de expansão das exportações dos produtos do setor de flores para esses países, incluídas no programa Florabrasilis.

Em relação aos EUA, observa-se que as importações de flores e plantas ornamentais mantiveram-se constantes de 1989 a 2001, em relação ao seu consumo doméstico, com base em 36 maiores estados americanos, de acordo com FLORICULTURE AND NURSERY CROPS SITUATION AND OUTLOOK YEARBOOK (2002). Por outro lado, nesse período, houve tendência de aumento nas importações de flores de corte para os EUA, conforme mostra a Figura 2(a). As importações de flores de corte do Brasil ainda possuem participação marginal para os EUA.

Ao se analisar o quanto essas representam no montante total norte-americano, observa-se que houve recuperação crescente a partir de 2001, já elevando a participação das exportações brasileiras para esse país de $0,02 \%$ para $0,12 \%$ em 2002 , provavelmente derivada da implantação do programa Florabrasilis. A produção doméstica de flores de corte dos EUA obteve queda de, aproximadamente, $9 \%$ ao ano, em relação ao consumo doméstico, tendo como referência o ano de 1989, o que pode ser observado na Figura 2(b). Esses fatores podem indicar que há perspectivas para a inserção de produtos importados (incluindo o brasileiro) nesse mercado, desde que se verifiquem os padrões de qualidade exigidos pelo consumidor norte-americano.

Dadas as características do mercado norte-americano, que tem direcionado suas importações de flores de corte para grandes distribuidores, há a possibilidade de se exportar produtos com qualidade e preços mais competitivos do que para a Holanda, cujas vendas concentram-se nos leilões, e há demandas de determinadas variedades de flores não necessariamente cultivadas no Brasil.

Apesar de iniciativas pontuais de alguns produtores e empresas, o setor de flores ainda é inexpressivo em termos de participação na pauta de exportações brasi- leiras. Contudo, há expectativas de que ampliará sua participação no mercado externo, com a implantação do Programa Brasileiro de Exportação de Flores e Plantas Ornamentais (Florabrasilis), criado em 2000.

Assim sendo, torna-se relevante realizar trabalhos voltados para a compreensão do papel de todos os integrantes da cadeia de exportação de flores e dos processos logísticos, que devem garantir que os produtos sejam entregues no destino final na quantidade exata, na hora determinada e pelo preço e qualidade acertados entre vendedor e comprador. A partir de então, poderiam surgir maiores vantagens competitivas em relação aos demais países concorrentes e, conseqüentemente, maior inserção em mercados consumidores internacionais, uma vez que os preços pagos são mais elevados do que os praticados no Brasil, em função de diferencial de renda e fatores culturais.

O objetivo deste trabalho é compreender o papel dos integrantes da cadeia de exportação de flores de corte e dos principais processos logísticos que a compõem.

\section{PRINCIPAIS ASPECTOS ECONÔMICOS E LOGÍSTICOS DA EXPORTAÇÃO DE FLORES DE CORTE}

Para analisar a importância da logística em cada uma das etapas dessa cadeia, neste estudo foram realizados levantamentos de dados primários e secundários, a fim de obter informações mais aprofundadas sobre as relações existentes entre os elos da cadeia. Os dados primários foram obtidos junto a especialistas do setor, por meio de entrevistas pessoais, com a aplicação de questionários previamente formulados. Os dados secundários foram coletados a partir de literatura nacional e internacional, compostas por livros, teses, artigos, relatórios e sites específicos, relacionados à exportação de flores.

\subsection{Principais componentes logísticos das exportações brasileiras de flores de corte}

$\mathrm{Na}$ exportação de flores de corte várias cadeias podem ser analisadas, dependendo do país de destino. A Figura 3 mostra os players da cadeia do Brasil para os EUA e para a Holanda. Estão inseridos os períodos médios de tempo entre as operações de cada um dos agentes, considerando apenas os trajetos região de Holambra-Campinas/São Paulo-Miami e região de HolambraCampinas/São Paulo-Amsterdam. Nota-se que em ambas as cadeias há envolvimento dos mesmos agentes no Brasil. 


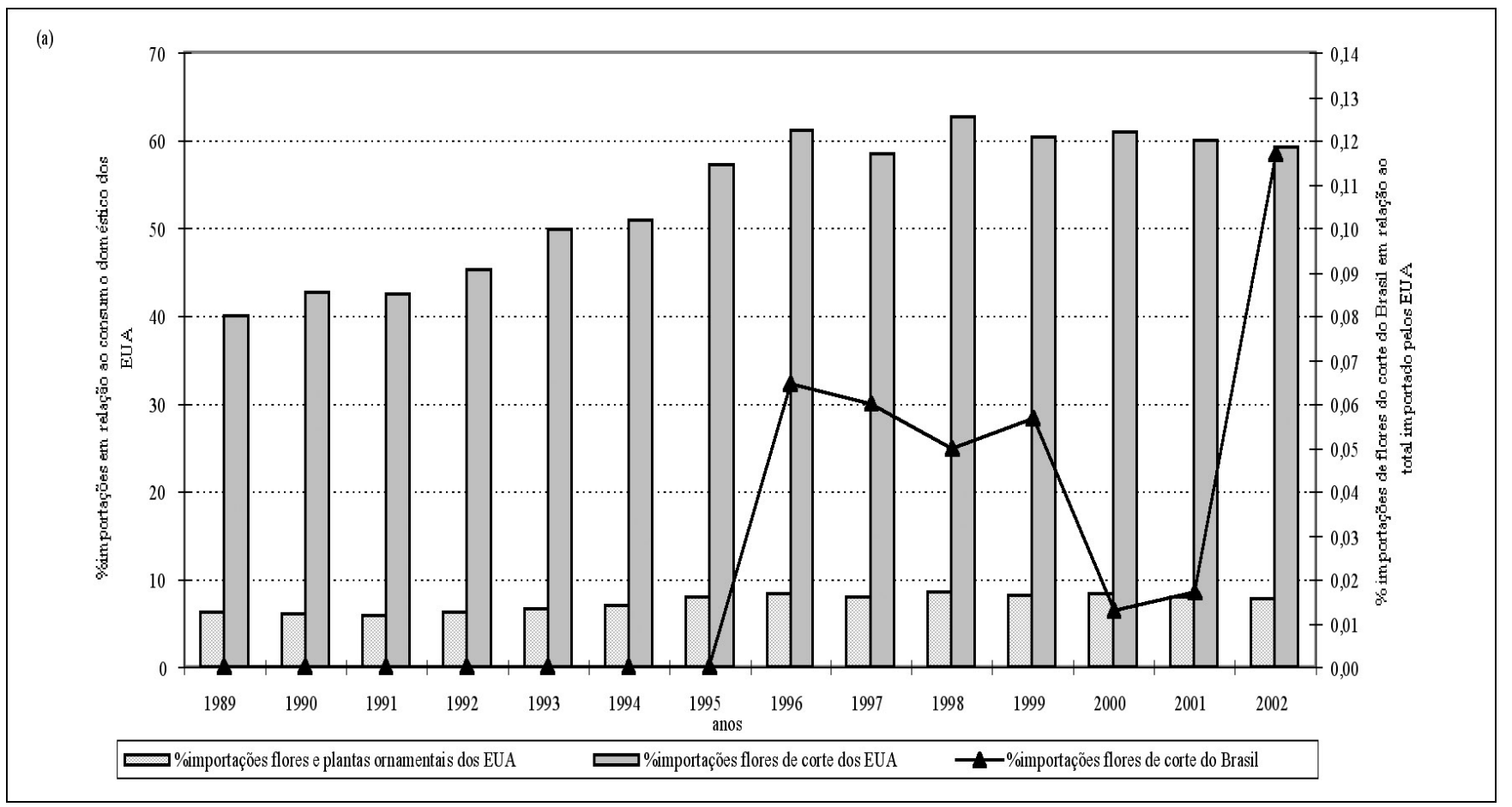

(b)

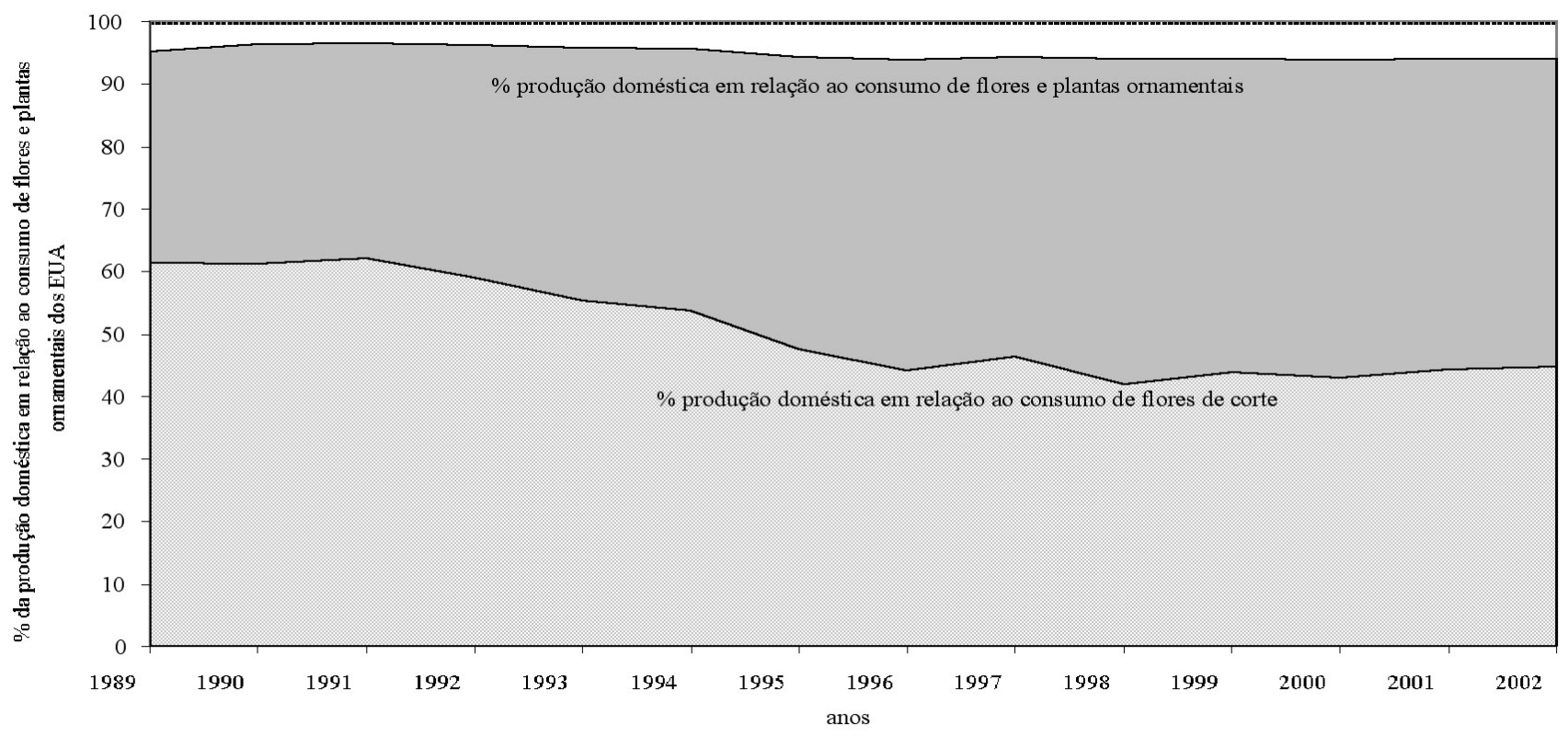

Fonte: FLORICULTURE AND NURSERY CROPS SITUATION AND OUTLOOK YEARBOOK (2002, 2003) e BRASIL (2004)

Figura 2. Porcentagem das importações (a) e da produção doméstica (b) de flores e plantas ornamentais nos EUA, em relação ao consumo doméstico, de 1989 a 2001. 


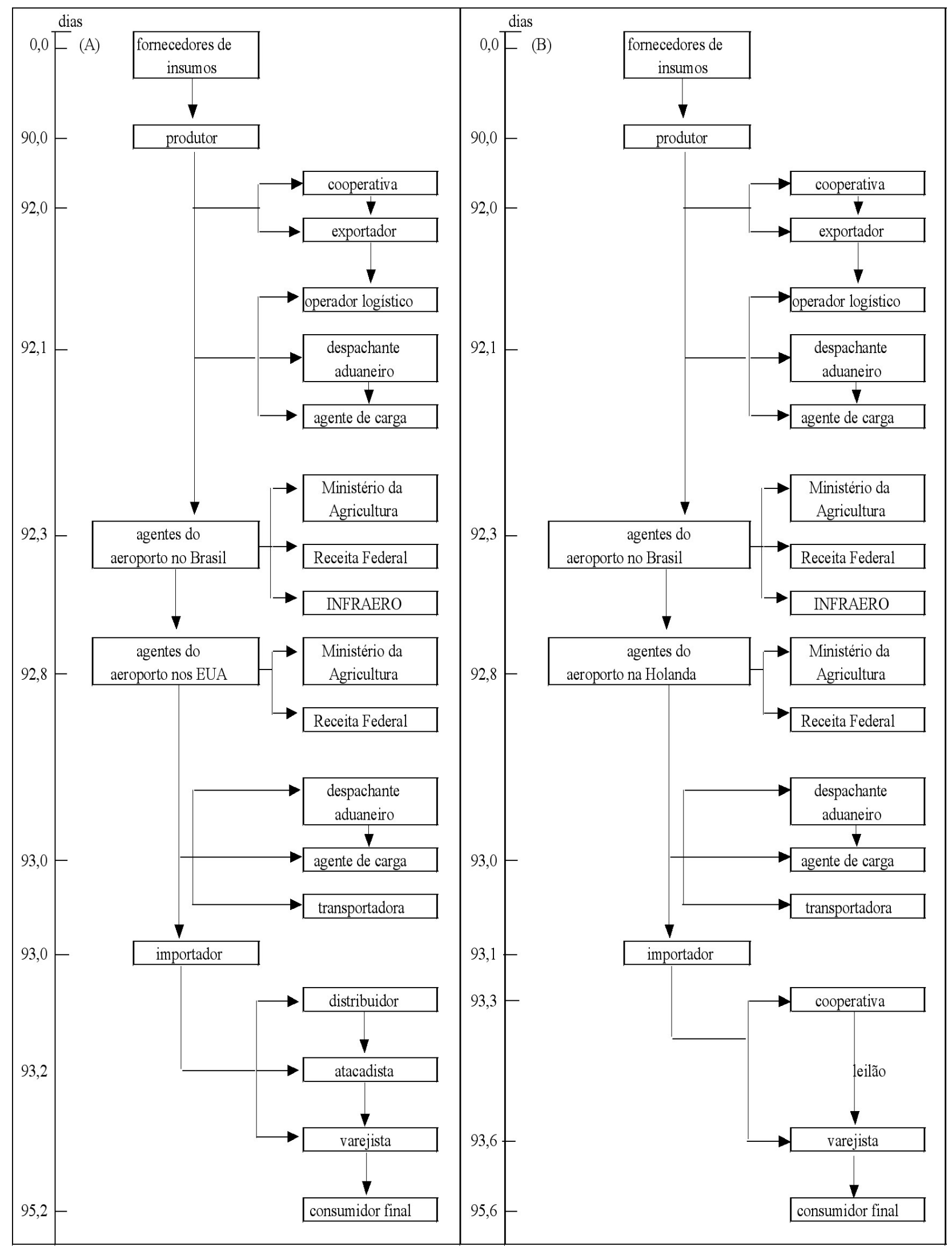

Figura 3. Cadeias de exportação de flores Brasil-EUA (A) e Brasil-Holanda (B), a partir de informações fornecidas por especialistas do setor. 
Se não ocorrerem entraves em cada uma das etapas, a diferença diz respeito basicamente aos mercados de países de destino, que possuem estruturas distintas de comercialização do produto. Apesar disso, o tempo total de entrega das flores até o consumidor final, em média, praticamente não varia muito - em torno de cinco a seis dias - sem considerar o processo de produção e o seu tempo de sobrevivência após a compra pelo último agente da cadeia.

Nesse caso, considerou-se o ciclo médio de 90 dias, relativo a flores, como gérbera e lírio, produzidas na região de Holambra ${ }^{4}$. As comerciais exportadoras são utilizadas para fazer a intermediação dos produtos no exterior, como alternativa para mercados em que as cooperativas não atuam de maneira efetiva. Algumas delas estão expandindo seus escritórios de representação para outros países, para estreitar as relações com atacadistas e importadores estrangeiros, agilizar o transporte das mercadorias e controlar a qualidade de seus produtos.

Os exportadores de flores podem se relacionar diretamente com produtores, cooperativas ou ambos e não se atêm a produtos de um determinado país ou região. Buscam produtos de melhor qualidade e preços competitivos, qualquer que seja sua origem. Em geral, esses agentes se relacionam diretamente com operadores logísticos, despachantes aduaneiros e agentes de carga, para que o produto seja embarcado na hora certa e entregue com a qualidade e prazos de entrega exigidos pelo cliente. Nesse caso, há a necessidade de interação com os procedimentos adotados pelos agentes do Ministério da Agricultura, Receita Federal e INFRAERO, para garantir o desembaraço aduaneiro da carga exportada. No caso de produtores, de pequeno a médio porte, que exportam pequeno volume de flores de corte por intermédio de determinado exportador, temse adotado o consórcio logístico, ou seja, é feito rateio, proporcional ao volume embarcado pelos produtores, das despesas cobradas por embarque, relativas à distribuição dos produtos até os aeroportos no Brasil e no exterior.

Observa-se que, nos EUA, há relacionamento de importadores com distribuidores e atacadistas, ao contrário da Holanda, na qual as flores de corte são destinadas aos leilões. Conforme COUTO (2002), esses leilões são conhecidos como clock e realizam a venda eletrônica de grande quantidade de flores, com média de seis mil transações por dia e 1,3 segundo por lote. O Veiling Holambra utiliza o mesmo sistema de comercialização empregado na Holanda e caracteriza-se por haver seleção mais rigorosa das flores comercializadas para atingir cotações de preços mais altos. No caso de venda direta para importadores ou distribuidores, o preço segue as tendências do mercado, com poder maior de negociação entre as partes para flores de melhor qualidade.

As perspectivas para a expansão do mercado no Brasil são positivas, pois, de acordo com BONGERS (2000), cada brasileiro gasta em média apenas US $\$ 3,80$ por ano com flores, enquanto gaúchos e cariocas consomem em média US\$13,70. Conforme esse autor, dentre os efeitos oriundos da primeira fase do Plano Real para a economia brasileira, a abertura das importações de produtos de menor valor agregado, como as flores artificiais, e a elevação do poder aquisitivo da população, fizeram com que os consumidores criassem novos hábitos de consumo, ampliando a vontade de adquirir produtos diferentes. Por outro lado, o aumento das viagens internacionais nessa época, principalmente por pessoas de classe média, levou à disseminação bastante rápida de hábitos estrangeiros quanto à compra de flores e plantas ornamentais.

O elevado consumo anual per capita nos principais países importadores de flores brasileiras, segundo BONGERS (2000), é, também, um estímulo à inserção do produto brasileiro no exterior. A Tabela 1 apresenta o consumo per capita de flores de corte de alguns países para 1990, 1994, 2000 e 2001. Nota-se que, de 1990 a 2001, houve expansão mais acentuada de seu consumo na Noruega, Suíça, Espanha, Reino Unido e Estados Unidos. Ao se considerar apenas 2000 e 2001, destacou-se a Eslovênia, com crescimento de $58,80 \%$. Há países, como a Alemanha, Dinamarca e Irlanda, que têm contraído sensivelmente o seu consumo nesses anos. De acordo com CENTRE FOR THE PROMOTION OF IMPORTS FROM DEVELOPING COUNTRIES (2002), o Reino Unido e a Alemanha continuam sendo os maiores importadores de flores de corte da Holanda.

Não houve, até recentemente, incentivos à exportação de flores, mesmo nas principais regiões produtoras brasileiras. Nota-se iniciativas pontuais para a expansão das exportações por parte de alguns produtores que tiveram acesso a algum canal de exportação mais específico. OKUDA (2000) ressalta que a maior integração entre todos os elos da cadeia só será atingida se o setor estiver mais organizado. Dentre os principais entraves relacionados à exportação brasileira, conforme SMORIGO (2000), pode-se relacionar problemas tributários, falta de padronização dos produtos e problemas de ordem fitossanitária.

\footnotetext{
${ }^{4}$ Informações mais detalhadas sobre este estudo poderão ser encontradas em ANEFALOS (2004).
} 
Tabela 1. Consumo per capita e taxas de crescimento de flores de corte de alguns países, 1990, 1994, 2000 e 2001

\begin{tabular}{|c|c|c|c|c|c|c|c|c|}
\hline \multirow[t]{3}{*}{ País } & \multicolumn{4}{|c|}{ Consumo per capita } & \multicolumn{4}{|c|}{ Taxa de crescimento } \\
\hline & \multicolumn{4}{|c|}{ US\$ } & \multicolumn{4}{|c|}{$\%$} \\
\hline & 1990 & 1994 & 2000 & 2001 & $1994 / 1990$ & $2000 / 1990$ & $2001 / 1990$ & $2001 / 2000$ \\
\hline Alemanha $^{1}$ & 39.38 & 49.30 & 35.18 & 34.59 & 25,20 & $-10,70$ & $-12,20$ & $-1,70$ \\
\hline Áustria & 32.50 & 63.47 & 39.11 & 40.00 & 95,30 & 20,30 & 23,10 & 2,30 \\
\hline Bélgica & 34.38 & 45.60 & 36.34 & 37.43 & 32,60 & 5,70 & 8,90 & 3,00 \\
\hline China & - & 0.00 & 0.45 & 0.55 & - & - & - & 22,20 \\
\hline Dinamarca & 39.88 & 36.36 & 39.6 & 35.27 & $-8,80$ & $-0,70$ & $-11,60$ & $-10,90$ \\
\hline Eslovênia & - & 16.64 & 17.04 & 27.06 & - & - & - & 58,80 \\
\hline Espanha & 10.63 & 15.41 & 15.63 & 16.24 & 44,90 & 47,00 & 52,80 & 3,90 \\
\hline Estados Unidos & 21.88 & 27.73 & 29.40 & 25.27 & 26,70 & 34,40 & 15,50 & $-14,10$ \\
\hline Finlândia & - & 36.97 & 31.88 & 33.30 & - & - & - & 4,50 \\
\hline França & 28.13 & 36.97 & 29.11 & 30.00 & 31,40 & 3,50 & 6,70 & 3,10 \\
\hline Grécia & - & 17.87 & 12.77 & 13.30 & - & - & - & 4,20 \\
\hline Holanda & 45.00 & 51.15 & 53.39 & 52.02 & 13,70 & 18,60 & 15,60 & $-2,60$ \\
\hline Irlanda & 29.55 & 9.24 & 25.36 & 23.76 & $-68,70$ & $-14,20$ & $-19,60$ & $-6,30$ \\
\hline Itália & 43.13 & 45.60 & 29.55 & 30.37 & 5,70 & $-31,50$ & $-29,60$ & 2,80 \\
\hline Japão & 51.25 & 44.98 & 30.45 & 34.13 & $-12,20$ & $-40,60$ & $-33,40$ & 12,10 \\
\hline Noruega & 30.00 & 65.94 & 51.25 & 52.02 & 119,80 & 70,80 & 73,40 & 1,50 \\
\hline Portugal & - & 0.00 & 14.29 & 14.59 & - & - & - & 2,10 \\
\hline Reino Unido & 21.88 & 22.18 & 33.3 & 32.94 & 1,40 & 52,20 & 50,60 & $-1,10$ \\
\hline Suécia & 36.88 & 39.44 & 30.18 & 33.76 & 6,90 & $-18,20$ & $-8,50$ & 11,90 \\
\hline Suíça & 46.88 & 112.77 & 81.61 & 79.91 & 140,60 & 74,10 & 70,50 & $-2,10$ \\
\hline
\end{tabular}

Fonte: adaptado de FLOWER COUNCIL OF HOLLAND (2002)

1 Os dados de 1990 referem-se à Alemanha Ocidental

Nesse sentido, algumas iniciativas foram feitas para melhorar o fluxo de informações na cadeia de flores e plantas ornamentais. Com a implantação da Lei de Proteção de Cultivares em 25/04/1997, empresas internacionais sentiram-se mais motivadas a investir no Brasil. Essa lei, no $9.456^{5}$, foi criada com o intuito de proteger os direitos de propriedade dos cultivares, com o detalhamento de todas as ações que devem ser executadas para que seja cumprida. SANTANA (1997) destaca que, em relação às empresas que criam variedades de rosas, já é prática comum a cobrança do direito autoral pelo seu cultivo em qualquer parte do mundo. Há casos de empresas que chegam a cobrar até um dólar por planta, de suas variedades cultivadas por outros produtores.
O Programa Brasileiro de Exportação de Flores e Plantas Ornamentais (FloraBrasilis) constitui-se em outra iniciativa recente. Originou-se do convênio entre o Instituto Brasileiro de Floricultura (IBRAFLOR) e a Agência de Promoção de Exportações (APEX), firmado em outubro de 2000, para que fosse conduzido em quatro anos nas regiões com produção organizada, com vistas a expandir o mercado brasileiro para Alemanha, Holanda, Japão e Estados Unidos. Conforme FLORES E PLANTAS ORNAMENTAIS (2001), foram selecionados os seguintes pólos de produção: Amazonas e Pará; Bahia e Espírito Santo; Ceará; Goiás e Distrito Federal; Minas Gerais; Paraná; Pernambuco e Alagoas; Rio de Janeiro; Rio Grande do Sul; Santa Catarina; São Paulo.

\footnotetext{
${ }^{5}$ Maiores detalhes sobre o seu conteúdo poderão ser encontrados em http://www.orplana.com.br/ leicultivares.htm
} 
Seu objetivo principal é elevar as exportações brasileiras dos 13 milhões de dólares (dados de 1999) para 80 milhões de dólares. Apesar do otimismo do setor frente ao crescimento de 30\% em 2003 (US\$ 19.4 milhões), conforme relatado mais recentemente por ALVES (2004) e KIYUNA et al. (2004), essa meta ainda está longe de ser atingida. Para isso estão sendo mapeadas a cadeia produtiva e as preferências dos consumidores; estão previstos investimentos em formação, capacitação e treinamento de mão-de-obra; buscar-se-á a criação de um selo de qualidade e de uma marca nacional, permitindo a qualificação do produto; e, haverá participação em feiras internacionais para promoção dessa marca com a distribuição de material impresso. As informações coletadas nesse programa serão armazenadas em um banco de dados que dará subsídios para pesquisas do setor de flores. Esse banco incluirá informações sobre os atacadistas e os varejistas, a demanda e as tendências do mercado mundial, direcionando melhor as ações dessa cadeia em termos de capacitação de mãode-obra, técnicas de manuseio, apoio logístico, adequação de produto e embalagem.

Também para contribuir para um efetivo aumento das exportações brasileiras por meio do desenvolvimento da floricultura, foi instituído em 3 de julho de 2001 o Programa de Desenvolvimento Sustentado da Floricultura (Resolução 2866 do Banco Central $\left.{ }^{6}\right)$. Esse programa, por meio de recursos do Banco Nacional de Desenvolvimento Econômico e Social (BNDES), disponibilizou 30 milhões de dólares para investimentos no período de 1 de julho de 2001 a 30 de junho de 2002, dando suporte financeiro à implementação do programa Florabrasilis. Além disso, o produtor poderá obter crédito para investimentos fixos e semifixos relacionados à implantação ou ao melhoramento de culturas de flores para a exportação, com prazo de carência de cinco anos, taxa de juros de $8,75 \%$ ao ano, e limite de $\mathrm{R} \$ 50$ mil por pedido, que pode ser reavaliado se houver comprovação da capacidade de pagamento do beneficiário, decorrido pelo menos um ano a partir da formalização do financiamento.

Além dessa preocupação com o processo produtivo, deve-se considerar, também, que a distribuição de flores de corte para outro país é realizada, principalmente, por avião e há vários procedimentos exigidos ao longo dessa cadeia para que esse produto chegue ao seu destino final em boas condições. Além do manejo adequado das flores durante a sua produção, na pós-colheita há cuidados que devem ser tomados para garantir armazenamento adequado do produto na propriedade. Nem todos os produtores que exportam flores temperadas, por exemplo, possuem câmaras frias ou realizam pré-cooling, apesar de necessitarem de temperaturas mais baixas para a manutenção de sua qualidade e para que tenham maior durabilidade. Atrelado a isso, ainda há outro fator que pode diminuir a competitividade do produto exportado, relativo ao uso de veículos não refrigerados utilizados para transportar as flores do produtor até as centrais de distribuição.

Em geral, há o armazenamento em câmara fria nas centrais de distribuição, e o produto chega ao aeroporto de Viracopos ou Guarulhos por meio de transporte rodoviário refrigerado, porém não há garantia de que esse produto continue sob as mesmas condições nos aeroportos, pois nesses locais não há controle rigoroso de temperatura para armazenamento de perecíveis. Exportadores, órgãos de fiscalização (Ministério da Agricultura, Receita Federal e INFRAERO) e companhias aéreas estão envolvidos nessa etapa.

Até março de 2004 esses aeroportos concentravam a quase totalidade das exportações para os EUA, de acordo com BRASIL (2004), sendo que entre 2000 e 2001 as flores de corte eram apenas exportadas por Guarulhos. Apesar disso, foram registrados problemas no armazenamento e paletização desses produtos em ambos os aeroportos, resultando em perda parcial ou total das flores exportadas, de acordo com informações do setor.

A partir de 2003 houve inversão da participação desses aeroportos, e Campinas tem concentrado por volta de $75 \%$ das exportações de flores de corte para os EUA. O aeroporto de Guarulhos concentrou a maioria dos embarques para a União Européia até dezembro de 2003, apesar de ter apresentado uma sensível redução ao longo dos anos. Essa situação foi alterada nos primeiros três meses de 2004, uma vez que esse aeroporto só embarcou cerca de $43 \%$ em relação ao total exportado no Brasil. O aeroporto de Fortaleza obteve crescimento de $69,40 \%$, aumentando sua participação de $26,80 \%$ em 2003 para 45,40\% em 2004 em relação ao total exportado de flores de corte brasileiras. Essa elevação provavelmente esteja relacionada aos incentivos da região para produção e exportação, principalmente de rosas ligadas à empresa Cearosa.

\footnotetext{
${ }^{6}$ Essa resolução está disponível em Banco Central do Brasil http://www.bcb.gov.br
} 
Em relação a esse programa de exportação, destacase o Estado do Ceará, que está incentivando a formação de consórcios de exportadores com o apoio da APEX. Para estimular a produção local de crisântemos e flores tropicais (tais como abacaxi ornamental, dracenas, helicônias) que agradam ao gosto mais exótico de estrangeiros, de acordo com ROSAS (2000), foi criado o projeto Agroflores, que permitiu aos produtores comercializarem seus produtos tanto no mercado interno quanto no exterior, com destaque para a Holanda, Alemanha e Estados Unidos, por intermédio de atacadistas de Miami. Conforme DEMARCHI (2001), apesar das rosas, cravos e cravinas ainda representarem em torno de $70 \%$ da demanda mundial, as flores tropicais já ganharam espaço nesse mercado, como é o caso de orquídeas, antúrios, bromélias, alpínias, musáceas e helicônias.

Ao se analisar o programa de exportação de flores brasileiras, nesse processo de qualificação e monitoramento do produto brasileiro, de acordo com MACHADO (2000), deve-se considerar, também, a rastreabilidade, que possibilita ao consumidor mais exigente a confiança no produto que está adquirindo. Permitirá, também, que se localizem possíveis falhas e se tomem medidas corretivas a custos mais baixos, a partir do conhecimento de todas as transações pelas quais o produto foi submetido até a sua origem. Na criação da marca nacional, esse componente pode se constituir num diferencial em relação aos demais países exportadores, facilitando, inclusive, a obtenção do selo ambiental, que é exigência do mercado europeu.

Deve-se destacar o papel da IBRAFLOR para estabelecer o padrão único de qualidade das flores brasileiras. A partir de discussões com a Câmara Setorial de Flores e Plantas Ornamentais do Estado de São Paulo, iniciadas em 1999, de acordo com MOTOS (1999), foram classificadas as vinte principais flores e plantas ornamentais, a partir de critérios que deverão constar nas embalagens dos produtos.

Como o cliente final é exigente, o transporte assume importância crucial em relação à distribuição do produto para o exterior, principalmente quanto aos prazos de entrega. Para que as flores cheguem ao seu destino em condições adequadas de comercialização, há necessidade de se conscientizar os agentes envolvidos nessa etapa para que se priorize o transporte de perecíveis. Por exemplo, a exportação de flores foi prejudicada em 2000 devido à greve de funcionários do Ministério da Agricultura, responsáveis pela fiscalização e controle fitossanitário de produtos agrícolas destinados ao exterior.
SMORIGO (2000) destaca que há treinamento especializado dos associados pertencentes a sistemas privados, como a cooperativa Holambra, com maior acesso a cursos de especialização e viagens técnicas à cooperativa. Dado que, de maneira geral, o cultivo de flores não demanda investimento alto de capital, uma vez que necessita de pequenas áreas para um ciclo rápido de produção, de acordo com GÓES (1997), há muitos produtores, principalmente associados aos sistemas de distribuição públicos (como CEASA, CEAGESP), que não investem em treinamento especializado dos seus funcionários.

Quanto maior o investimento na marca, maior é a sua especificidade, conforme confirmado por SMORIGO (2000). Assim, deve-se analisar cuidadosamente como esses processos de criação de marcas ocorreram em outros países, como a Holanda, para que sejam adequadamente implantados no Brasil. Um exemplo de sucesso, segundo CALÇADOS (2002), é a Cooperativa de Flores Holambra, que já possui há alguns anos uma marca coletiva para produtores associados, sem que as marcas individuais sejam prejudicadas.

Para que o Brasil atinja mercados mais exigentes, deverá investir no certificado ambiental (selo verde), que já é almejado pelos concorrentes colombianos e equatorianos; caso contrário, terá dificuldade de ampliar o mercado a longo prazo. Para isso, vários elementos, tais como os sistemas de produção e transporte, os tipos de semente, pesticidas e insumos utilizados, devem ser considerados no planejamento dos investimentos. No caso de flores, para que se realize controle mais intensivo de pragas e doenças, exigem-se monitoramento constante e controle freqüente dessas adversidades. Outros fatores que podem contribuir para reduzir a incerteza são o manejo adequado da cultura e o emprego de tecnologia. Quanto a esses dois últimos quesitos, SMORIGO (2000) detectou que os produtores que utilizam sistemas de distribuição públicos, com menor nível tecnológico, estão mais suscetíveis à incerteza.

Segundo informações setoriais, a exportação de flores apresenta outros fatores limitantes relevantes, tais como a inexistência de câmaras frias nos aeroportos e nos próprios compartimentos de carga dos aviões.

De acordo com o estudo de FLORABRASILIS (2002), 51,70\% dos exportadores pesquisados estão localizados no Estado de São Paulo e utilizam em sua maioria o modal aéreo (80\%) para exportar seus produtos. A partir do cadastro da Secretaria de Comércio Exterior do Ministério do Desenvolvimento, Indústria e Comércio, foram selecionadas 29 empresas exportadoras, para a posterior realização do levantamento de campo, nos meses de abril a outubro 2002, para a coleta dos dados. 
Foram apontados os seguintes entraves nesse estudo para o Brasil: problemas sérios na infra-estrutura para exportação, relacionados ao certificado fitossanitário de origem, câmaras frias nos aeroportos e processo de liberação da carga nos aeroportos; importação de matrizes; qualidade do produto; idoneidade do importador; alto custo operacional para pequenas remessas; carência de produtos para elevar as exportações; preços de frete elevados; não conhecimento do produto brasileiro no exterior; falta de informação do mercado de destino; inexperiência do aeroporto e de importadores com relação ao produto.

Na Holanda, ELSHOF (1998) detectou entraves na produção, destacando-se entre eles: limitações no clima; necessidade de cultivo em estufas; forte dependência de fontes de energia não-renováveis; alto custo da terra; escassez de água de irrigação; emissões de fertilizantes e defensivos no solo, água e ar; mão-de-obra cara; pequeno conhecimento de marketing; dificuldade dos produtores obterem informações atualizadas do mercado.

De acordo com SEMBOJA, MBELWA E BONAVENTURA (2000), foram identificados problemas na exportação de flores na Tanzânia, referentes ao transporte, em função de tarifas alfandegárias elevadas quando comparadas ao Quênia (US\$2,00/kg contra US\$ $1,50 / \mathrm{kg}$, respectivamente); à burocracia no despacho da documentação e estradas ruins até Nairobi (onde se localiza o aeroporto); a sistemas de controle de qualidade precários, apesar de os produtores terem recebido treinamento sobre controle de qualidade e embalamento do produto. No Brasil essas tarifas também são consideradas elevadas, e para os EUA variaram muito após o atentado de 11/09/2002. A sua oscilação está diretamente ligada ao excesso ou falta de demanda de carga nos vôos.

A cadeia de exportação de flores de corte possui uma estrutura complexa, pois envolve a interação de muitos agentes num curto período de tempo em que se deve minimizar a alta perecibilidade do produto e maximizar a sua qualidade até que atinja o consumidor final. Como as exportações ainda são incipientes, vários ajustes, inclusive logísticos, são necessários para que a cadeia melhore gradativamente seu desempenho ao longo do tempo.

Portanto, esforços contínuos dos órgãos competentes deverão ser feitos, para que ocorra maior transparência do sistema como um todo e, também, dos demais agentes envolvidos nos processos, para que haja maior cooperação entre os parceiros, com conseqüente redução dos gargalos da cadeia, com vistas à expansão da comercialização desses produtos no mercado externo.

\section{CONSIDERAÇÕES FINAIS}

O setor de flores necessita de grande interação entre os agentes, para que as exportações brasileiras possam ser viabilizadas a longo prazo. Para isso, o aprimoramento de cada uma das etapas deve ser o foco central dos diversos integrantes envolvidos nessa cadeia, e as experiências de outros países podem ser relevantes para que se identifiquem pontos fracos em comum e se tome conhecimento de como os problemas foram resolvidos ou amenizados. Apesar de ser vital, é um processo árduo, que envolve mudanças culturais e tecnológicas para que os padrões internacionais de qualidade e cuidados póscolheita sejam seguidos, garantindo aceitabilidade do produto brasileiro no exterior.

Para que se tenha vantagem competitiva em relação a outros países, a preocupação com a eficiência logística deve ser muito maior, principalmente quando se trabalha com flores de corte, que possuem menor durabilidade ao se comparar com outros produtos não-perecíveis atualmente exportados pelo Brasil. Há, também, vários cuidados no seu manuseio, relacionados à colocação nas embalagens e o acondicionamento adequado em caminhões e aviões, com controle de temperatura dentro dos veículos que transportam o produto.

Tanto a cadeia de flores temperadas quanto a de tropicais exigem um monitoramento constante do produto ao longo de toda a cadeia, para que o processo logístico seja otimizado em todas as etapas da exportação, garantindo a obtenção de preços mais competitivos no mercado externo. Isso também pode se refletir internamente, uma vez que a oferta de produtos diferenciados vendidos no mercado doméstico poderá suprir demandas de segmentos específicos e atingir preços melhores.

\section{REFERÊNCIAS BIBLIOGRÁFICAS}

ALVES, T. Flores brasileiras batem recorde de exportação. O Estado de São Paulo. Negócios \& Oportunidades. São Paulo, 01 fev. 2004. p.1.

ANEFALOS, L. C. Modelo insumo-produto como instrumento de avaliação econômica da cadeia de suprimentos: o caso da exportação de flores de corte. Piracicaba: Escola Superior de Agricultura "Luiz de Queiroz", Universidade de São Paulo, 2004. 210p. Tese (Doutorado)

BARLETTA, A. Shipping flowers via air. FloraCulture International, v.5, n.3, p.17-95, 1995.

BONGERS, F.J.G. O desenvolvimento da floricultura no Brasil. IBRAFLOR Informativo, v.5, n.19, 2000. http: //www.flortec.com.br/ artigo04.htm (19 ago. 2001) 
BRASIL. Secretaria de Comércio Exterior (SECEX). Exportação e importação brasileira de plantas vivas e produtos de floricultura: 1989-2003. Brasília, 2004. http://aliceweb.\%20mdic.gov.br/consulta_nova/ resultadoConsulta.asp (16 fev. 2004)

BRITISH COLUMBIA. An overview of the BC floriculture industry. Abbotsford: Fact Sheet, Oct. 2003. http:// www.agf.gov.bc.ca/ornamentals/publications/documents/ overview/floriculture/2003oct28.pdf (18 Feb. 2004)

CALÇADOS e flores. Panorama Brasil, 03 jun. 2002. http: //home.linkway.com.br/ noticia.jsp?idnoticia=3730 (17 jul. 2002)

CENTRE FOR THE PROMOTION OF IMPORTS FROM DEVELOPING COUNTRIES. EU Market Survey 2002: cut flowers and foliage. Rotterdam: CBI, Oct. 2002. 87p. http://212.133.165.5/dokumanlar/dtc/ulke_rehberleri/ pdf/survey_cut_flowers_2002.pdf(26 May 2004)

CLARO, D.P. Análise do complexo agroindustrial das flores do Brasil. Lavras. Universidade Federal de Lavras, 1998. 103p. Dissertação (Mestrado).

COUTO, M. Vida longa às flores. Revista Abrava, v.26, n.196, 2002. http://www.portalabrava.com.br/news/ revista/ler_196.asp (19 fev. 2003)

DEMARCHI, C. Guerra das flores movimenta os trópicos. Gazeta Mercantil Latino-Americana, 28 fev./04 mar. 2001. p.7-8.

ELSHOF, P. The dutch flower sector: structure, trends and employment. Geneva: International Labour Organization (ILO), Food Research and Consultancy, 1998. http: //www.ilo.org/public/english/dialogue/ sector/papers/ flrsect/flrsect5.htm (17 Apr. 2004)

FLORABRASILIS. Relatório do diagnóstico da produção de flores e plantas ornamentais brasileira. Campinas: IBRAFLOR, 2002. (Compact disc).

FLORES e plantas ornamentais. Agronegócios. Campinas, 2001.http://www1.bb.com.br/por_noticias_publicacoes/ rce pubRCEfichaartigo (26 ago. 2001)

FLORICULTURE AND NURSERY CROPS SITUATION AND OUTLOOK YEARBOOK. Washington: USDA, 2002. 107p.

FLORICULTURE AND NURSERY CROPS SITUATION AND OUTLOOK YEARBOOK. Washington: USDA, Sep. 2003. 24p. http://www.ers.usda.gov/publications/ flo_sep03/ flo02.pdf(24 Nov. 2003)

FLOWER COUNCIL OF HOLLAND. Flower Council. http: //www.flowercouncil.org (02 Feb. 2002)

GOÉS, V.L de. A comercialização internacional de flores e a formação de preço. São Paulo: Escola de Administração de Empresas de São Paulo, Fundação Getúlio Vargas, 1997. 143p. Dissertação (Mestrado).
HUGHES, A. Retailers, knowledges and changing commodity networks: the case of the cut flower trade. Geoforum, v.31, n.2, p.175-190, 2000.

KIYUNA, I.; COELHO, P.C.; ÂNGELO, J.A.; ASSUMPÇÃO, R. de. Parceiros comerciais internacionais da floricultura brasileira, 1989 a 2002. Informações Econômicas, v.34, n.5, p.7-34, 2004.

LUCAS, K. Em busca do "selo verde". http:// www.tierramerica.net/2001/0603/ pacentos.shtml (06 mar. 2001)

MACHADO, R.T.M. Rastreabilidade, tecnologia da informação e coordenação de sistemas agroindustriais. São Paulo: Faculdade de Economia, Administração e Contabilidade, Universidade de São Paulo, 2000. 239p. Tese (Doutorado).

MILLER, M.N. Opportunities and challenges for floricultural producers selling to a changing marketplace. Agricultural Outlook Fórum 2003. Arlington:USDA, 2003. p.1-5.

MOTOS, J. Padrão IBRAFLOR de qualidade. IBRAFLOR Informativo, v.5, n.20, 1999. http://www.flortec.com.br/ artigo02.htm (19 ago. 2001)

MOTOS, J. A importância dos materiais de propagação na qualidade das flores e plantas. IBRAFLOR Informativo, v.6, n.21, 2000a. http://www.flortec.com.br/ artigo05.htm (19 ago. 2001)

MOTOS, J. A produção de flores e plantas ornamentais no Brasil e no mundo. Flores de Corte, 2000b. http: //www.flortec.com.br/artigo10.htm (19 ago. 2001)

OKUDA, T. Mercado de flores tem grande potencial no país. Frutas e Legumes, v.1, n.3, p.22-26, 2000.

PATHFAST. International floriculture trade statistics. Erwarton, 2001. http://www.pathfastpublishing.com/ ITS20/ITS21 (15 Mar. 2004)

ROSAS e espécies tropicais atraem compradores nos EUA e na Europa. Revista Update, n.363, 2000. http: //www.amcham.com.br/revista/363/exportacao.html (27 set. 2001)

SANTANA, E. Nem tudo são rosas. Revista Tecnologística, v.2, n.23, p.18-24, 1997.

SEMBOJA, H.H.H.; MBELWA, R.; BONAVENTURA, C. The cut-flower industry in Tanzânia. Geneva: International Labour Office, 2000. (Working paper, 152) http://www.ilo.org/public/english/dialogue/sector/papers/ tanzflow/index.htm (17 Apr. 2004)

SMORIGO, J.N. Análise da eficiência dos sistemas de distribuição de flores e plantas ornamentais no Estado de São Paulo. Piracicaba: Escola Superior de Agricultura "Luiz de Queiroz", Universidade de São Paulo, 2000. 132p. Dissertação (Mestrado).

WALT, V. Mercado das flores. National Geographic Brasil, v.2, n.4, p.96-113, 2001. 